\title{
Structural Equation Model on Work Engagement of Non-Commissioned Police Officers
}

\author{
Rogelio A. Lovina, $\mathrm{PhD}^{1}$, Rinante L. Genuba, EdD²; Leo C. Naparota, $\mathrm{PhD}^{3}$
}

${ }^{1}$ Jose Memorial State University, Zamboanga del Norte, Philippines

${ }^{2}$ University of Mindanao, Davao City, Philippines

${ }^{3}$ Andres Bonifacio College, Dipolog City, Philippines

\begin{abstract}
This research was aimed at determining the best fit model of work engagement of non-commissioned police officers of Zamboanga del Norte. Specifically, it established the interrelationship among emotional intelligence, self-esteem and safety management of non-commissioned police officers in Zamboanga del Norte. This study used quantitative research design and structural equation model. The data were collected from 400 non-commissioned police officers presently assigned in the province of Zamboanga del Norte. Findings revealed that the level of emotional intelligence, self-esteem, work engagement were high and very high for safety management. Results also revealed that there were significant relationship between emotional intelligence and work engagement, self-esteem and work engagement, safety management and work engagement. Moreover, emotional intelligence, self-esteem and safety management are predictors of work engagement. Likewise, work engagement is best anchored on emotional intelligence which signifying that the extent of emotional intelligence could mean higher of work engagement. Additionally, articulated the latent variable safety management representing the measured variables administration, accountability, facilities/equipment/materials problems and employees as the best fit model for work engagement of noncommissioned police officer.
\end{abstract}

Keywords - criminal justice, emotional intelligence, self-esteem, safety management, work engagement, Philippines.

\section{INTRODUCTION}

Working as member of the Philippine National Police is a prestige. Work engagement of police officer is highly stressful as they always have to face challenges to their life by taking risk in their daily work (Shaikh \& Kapadi, 2014). The high risk of job burnout in the police officer's work engagement is apparent (Basinska \& Daderman, 2019). The burnout is viewed as its opposite and is characterized by low emotional energy (Bakker, Schaufeli, Leiter, \&Taris, 2008). Disengaged police officer become disconnected from their jobs and conceal their real identity, ideas and emotions during role performances (Olivier \& Rothmann, 2007). In the police organization, police officers oftentimes frequently work long, extended, and irregular shifts of duty (Waggoner, 2012). In modern organization, the need for an inspired and motivated workforce capable of going "the extra mile" is an issue of increasing importance in the group (Bakker \& Demerouti, 2008).

This study on work engagement is significant for it would help assess the present situation of the men in uniform of Philippine National Police. Work engagement is considered to have great significance for both police officers and organizations (Steger, Littman, Miller, Menger \& Rothmann, 2013). Consequently, work engagement is necessary of the police officers for the success of the PNP organization. Police officers are one of the numerous professions that are important for the growth of domestic economic and social development because they have a main role and power in maintaining peace, providing security for the public, preserving common assets for people in the community and physical needs in human society (Chokprachakchat, 2011). 
Obviously, there have been several work engagement studies linked with different variables. In the study of Zhu, Liu, Guo, Zhao, and Lou (2015) linked work engagement with emotional intelligence. Emotional intelligence is the capability of a person to manage his or her emotions and have the ability to control the emotions of others as well. Whereas, Rotich (2016) linked work engagement with self-esteem. Self-esteem is a positive assessment of one's personality. On the other hand, work engagement may be link with safety management. Safety management could be used to forecast worker engagement levels and worker engagement levels commitment as mediators between the safety management system and safety performance results such as accident rates (Wachter \& Yorio, 2014).

Work engagement brings a new interest in the field of research in the academe. The literature has a gap with regard to work engagement of non-commissioned police officers. At this point of view, as a consequence of diverse populations, treatment and research designs, it is difficult to draw conclusions and generalization from the available literature. This challenge the academe researchers, to assess work engagement of non-commissioned police officers. Since there was no study conducted relative to work engagement of non-commissioned police officers. It is for this reason, that this study had been conducted among noncommissioned police officers in the Province of Zamboanga del Norte. This study aimed to add the body of knowledge and develop a new model which would enrich work engagement of non-commissioned police officers.

\section{Research Objective}

The purpose of the study was to construct a structural equation model on work engagement through emotional intelligence, safety management and self-esteem. Specifically, this study dealt with the following objectives: to assess the level of emotional intelligence of noncommissioned police officers in terms of: self-awareness, managing emotions, motivating oneself, empathy, and social skill; to measure the level of safety management of noncommissioned police officers in terms of: administration, accountability, facilities/equipment/materials, procedures, problems, and employees; to evaluate the level of self-esteem of non-commissioned police officers in terms of: performance self-esteem, social self-esteem, and appearance self-esteem; to ascertain level of work engagement of non- commissioned police officers in terms of: vigor, dedication, and absorption; to determine the significant relationship between: emotional intelligence and work engagement, safety management and work engagement, and self-esteem and work engagement; to determine the singular and combined influence of the independent variables to the work engagement of the non-commissioned police officers and to determine what model best fits for work engagement of the non-commissioned police officers.

\section{LITERATURE REVIEW}

\section{Emotional Intelligence}

Research have showed that emotions are great contributory factors to enhance performance and better decision making in our daily works. Accordingly, emotional intelligence is the ability of people to acknowledge their own and other people's emotions, discern between distinct feelings and properly label them, use emotional data to direct their thinking and behavior, and handle and/or modify emotions in order to adapt to their settings or attain their objectives (Coleman, 2008). In its simplest word, refers to the capacity in ourselves and others to acknowledge and control feelings to make effective decisions (Dhani\& Sharma, 2016).

Theoretical explanation indicates that emotional intelligence significantly relate to police works. Study revealed that emotional intelligence is essential for employment that requires communication with others, inside or outside the organization (Al Ali, Garner, \& Magadley, 2011). Igbinovia (2016) stated that self-awareness is considered as the first stage of emotional intelligence as a subset of social intelligence. Self-awareness typically cited as the starting point for emotional intelligence discovery (Nelson \& Low, 2011). Singh (2013a) noted that selfawareness is the fundamental basis on which emotionally smart conduct germinates and that self-awareness relates to the capacity to read one's own feelings and recognize their effect on decision-making. Emotional intelligence they are crucial for police officers as their work is essentially in direct contact with the individuals of the society and the individual making the touch needs to have a proper knowledge for a satisfactory contact (Aremu \& Tejumola, 2008).

Emotional intelligence can be viewed along broad spectrum which speaks louder than using cognitive skills such as intellect and problem solving (Conroy, 2018).Emotional intelligence plays an important role as a 
counter measure to the ever present volatility, uncertainty, complexity, and ambiguity demands of the contemporary police officer (Javidi\& Ellis, 2016). Employees with high emotional intelligence levels are more capable of controlling feelings that make them feel more confident and in command of their job's task demands (Sy, Susanna, \& O'Hara, 2006). Individuals high in emotional intelligence effectively understand, perceive emotion and successfully utilize their emotions for purposeful action (Law, Wong \& Song, 2004).

Managing emotions is an art (Udoh, 2017). It involves possessing a working understanding one's feelings, as well as devising techniques of relating with such emotions. Emotions are a big part of life for us all (Bacon, 2016). The mind interacts with our experience of events that are or are not in line with our personal goals to engender emotion (Scherer, Schorr, \&Johnstone, 2001). The high emotional intelligence shows high degree of workplace commitment as these individuals are able to handle their feelings so that they are less engaged in disputes, create stronger interpersonal relationships, are hopeful and align their objectives with organizational objectives (Deshwal, 2015). Emotional intelligence of noncommissioned police officers implies a considerable level of work, control and management of emotions (Monier, 2014; Al Ali, Garner, \&Magadley, 2012; Dar et al., 2011).

Accordingly, human beings are innately goaldirected. Experience and prospecting lead us to set targets that would create the nations of the world that we have assessed favorably or negatively, and we are inspired to behave (Crum II, 2017). The effectiveness in managing emotions means effectiveness in self-leadership which translates to effectiveness in leading people. Inability to manage emotions can be disastrous for both the leader and the people being led and the society (Udoh, 2017).

Self-awareness associated with the process of selfperception emphasized a greater understanding of one's own strengths and weaknesses by interacting, communicating, engaging and responding to others (Avolio, Gardner, Walumbwa, Luthans, \& May, 2004; Kernis, 2003). It also shows the state of one's attention in which he / she directs this consciousness to some component of his / her own which leads to self-awareness (Hannah, Avolio, \&Walumbwa, 2011). Self-awareness should be established significantly to achieve high performance success in work engagement. The higher level of emotional intelligence leads employees to align with the goals and objectives of the organization (Sinha, 2016).

\section{Safety Management}

Safety management relates to concrete safety procedures, responsibilities and efficiency (Mearns, Whitaker, \&Flin, 2003). Good occupational safety management can have a beneficial impact not only on accident rates but also on the factors of competitiveness and economic results (Fernández-Muñiz, Montes-Peón, \&Vázquez-Ordáz, 2009). While "safety" is a familiar term which It varies from individual to individual: To the traveling public, it merely implies to reach one's destination without getting hurt (Stolzer, Halford, \&Goglia, 2008).

In the field of police work, risk is always a chance, and it is extremely unpredictable, because the potential to become a victim of violent encounters, the need for support from other peers and the lawful use of violence to fulfill the mandate of the police all contribute to a subculture that emphasizes courage, which is eventually linked to perception and action (Grossman, 2017).

In addition, the work of police officers is fundamental to the achievement of balance in society, and it is therefore important to understand any dangers or associated work risk factors regarding this category of personnel (ACHIM, 2018). Mearns et al. (2003) noted some prevalent theme of safety management practices: commitment to safety leadership, security communication, health and security goals, training needs, rewarding results, and participation of employees. Establishing a safety culture implies that employees are constantly conscious of the risks and dangers in the workplace, including those that they themselves produce (DeBoard, 2015).

On the other hand, the term safety management is a feature that enhances the efficiency of the business by anticipating operational, procedural or environmental hazards and threats before they happen (Sheahan, 2017). Today, safety management is no longer treated as secondary in the business context rather it is treated as a culture (Misnan\& Mohammed, 2007). This situation will greatly influence the employees' perception towards occupational safety and health management in the organization (Rhaffor, Saparuddin, \& Maidin, 2018). Hence, safety management practices are the most effective way in reducing the number of unsafe conditions (Aksorn \& Hadikusumo, 2008).

Accountability is a willingness to accept responsibility for our actions (Staff, 2013). The concept of accountability means that the actors held responsible have 
responsibilities to behave in a manner that is compatible with accepted norms of conduct and that they will be punished for failing to do so (Grant \&Keohane, 2005). Accountability is believed to be improved by the advent of competition in service delivery, for instance through a clear division of responsibility for policy definition, service provision and tracking (Cavill \& Sohail, 2007). Accountability is a form of liability that refers to whom and for what and what is accountable, which is understood as the duty of the holder of the faith to provide accountability, presenting and reporting happenings that are his responsibility to the party who provides the trust has the authority to hold such accountability (Khotami, 2017).

\section{Self-esteem}

Self-esteem is literally described by how much value individuals put on themselves (Baumeister, Campbell, Krueger, \&Vohs, 2003). In psychology, the word is used to define a person's general self-esteem or personal value. In other words, how much you enjoy and love yourself (Cherry, 2018). Self-esteem plays a significant part in the motivation and achievement of individual lives. People with high self-esteem are doing better than others for some employment and assignments. People with high self-esteem sometimes do better than individuals with low self-esteem in organizations. People with high self-esteem are more prepared to choose their own approaches than others, and are more responsive to situational indications that indicate when to continue and when to move towards a more successful option (Baumeister, et al., 2003)

On the other hand, self-esteem has something to do with the general meaning of the value or importance of a person. A measure of how much a person "values, approves, appreciates, awards, or likes him or herself" can be regarded as such (Adler \& Stewart, 2004). In every sphere of life, selfesteem is essential and can be regarded a fundamental human need. Self-esteem improves personal safety levels and is defined as a protective factor against risk behaviors. There is a need for police agencies to select police applicants who have high self-esteem. Police officers with low self-esteem may be less likely to be tolerant of or connect with citizens who are viewed as different and they may be reluctant to move toward positive interactions with diverse or different populations. Low self-esteemed individuals are the least prepared to accept differences (Charles, 2008).
In addition, it is critical to use psychological screening tests to assess self-esteem and select officers with high self-esteem (Bartol\&Bartol, 2004; Woody, 2005). Sedikides and Gregg (2003) suggested that self-esteem relates to the perception or subjective assessment of the individual's own self-worth, the emotions of self-respect and self-confidence, and the extent to which the person holds favorable or negative opinions of himself.

Police officers high self-esteem is more skilled to work in challenging circumstances and is less susceptible to stress issues. Specific suggestions are produced to improve police officers ' self-esteem. In the fields of anti-crime and non-criminal operations, a sense of competence may be improved. There are also suggestions for increased data on cases and the neighborhood, training for expertise in stress situations, improving the position of the patrolman in the department, and developing mutual respect within the society. Improving self-esteem will also enhance the police officer's efficiency (Stotland, 2016).

Self-esteem relates to the perception or subjective assessment of the individual's self-esteem, self-respect and self-confidence, and the extent to which the person holds favorable or negative opinions about self-esteem (Sedikides\& Gregg, 2003). Self-esteem is also described as a worldwide self-assessment barometer incorporating cognitive assessments of overall self-esteem and emotional self-experience related to these worldwide assessments (Murphy, et al., 2005).People with strong self-esteem are more likely to continue in the face of hard assignments than low self-esteem (Baumeister, et al., 2003).

In addition, performance self-esteem of police officers is linked to punishment and acts as a protective factor that undermines the adverse impact of violent victimization on punishment. Police policemen who were violently assaulted in the last year revealed greater rates of punishment than non-victims. In addition, participants with repeated experiences of victimization have been the most punitive. While greater rates of professional self-esteem were indeed associated with less punishment, the suggested protective effect of the professional self-esteem of police officers could not be confirmed (Ellrich, 2016).

\section{Work Engagement}

Work engagement is often described as a favorable, fulfilling, work-related state of mind that is described by vigor, dedication and absorption (Schaufeli, Salanova, 
Gonzlez-Roma, \& Bakker, 2002). In principle, work engagement captures how employees experience their job: as stimulating and vigorous, and as something they really want to devote time and effort, described as vigor; as a meaningful and meaningful pursuit, described as dedication; and as engrossing and fully focused, described as absorption.

On the other hand, work engagement is essential for the organizational success (Budihardjo, 2015; Harvard Business Review Analytic Services, 2013).Engaged workers are more productive (Bakker \&Demerouti, 2007). Work engagement is described as an energetic state in which the worker is committed to outstanding job results and is confident of its efficacy (Schutte, Toppinen, Kalimo, \&Schaufeli, 2000). The concept of engagement is also applicable to police work. Police officers tend to experience stressful works compare to other occupations due to the nature of their jobsuch as having long working hours,dangerous missions, job rotation or work mobility and unstable workplace assignment.

It was noted that police officers work in a very stressful environment, strategies to improve the beneficial relationship between work and home, the focus should be on enhancing employment resources to allow staff to deal demands at work to increase their level of work engagement and satisfaction (Mostert, 2006). The police officers around the world clearly indicates multiplied stress, they are in the greatest degree as victims of job burnout (Agolla, 2009).Rothmann and Storm (2003) a large cross-sectional study was performed among 1,910 South African police officers and discovered that committed police officers are focused on problems, taking active measures to try to remove or rearrange stressors. Studies done by Xanthopoulou, Bakker, Demerouti, and Schaufeli, (2007b) revealed that engaged employees are highly self-efficacious, optimistic and believe they can satisfy their needs by participating in roles within the organization.

Notably, work engagement is a motivational idea: engaged employees want to succeed, feel obliged to strive for difficult objectives, and commit themselves to achieving those objectives (Valtteri, 2014). Employees have continuously shown that they are more productive, lucrative, safer, healthier, and less likely to quit from their employer (Fleming \&Asplund, 2007; Wagner \& Harter, 2006). If one is not engaged at work, it may mean they are burned out (Hakanen\&Schaufeli, 2012; Schaufeli, Salanova, GonzalezRoma, \& Bakker, 2002); and burnout, a sub-variable of compassion fatigue, has been linked to violent behavior in police officers (Blumenstein, Fridell, \& Jones, 2012).

\section{RESEARCH METHOD}

In this research, the researcher was utilizing quantitative non-experimental design research method. In the generation of the best fit model, structural equation model (SEM) was used. Model (SEM) as noted by Lomax and $\mathrm{Li} \mathrm{(2013)}$ as well as Panes, Gempes, and Genuba (2017) is a quantitative method that includes aspects of various assessment of dependency relationships and exploratory factor analysis that represent unmediated model-factors with various variables to simultaneously assess a sequence of interconnected dependency interactions. On other hand, this investigation also known as path analysis with latent variables and is now a regularly used method for representing dependency (arguably "causal") relations in multivariate data in behavioral and social sciences (McDonald \&Ho, 2002). This research therefore utilizes Structural Equation Modeling (SEM) because SEM can be used to evaluate the data on work engagement connection among emotional intelligence, safety management and self-esteem among noncommissioned police officer of chosen police station in the province of Zamboanga del Norte.

Since this study aimed to assess the stress management in an organization among the non-commission police officer, a random sampling was used to analyze the number of city and municipal police stations. To identify the 400 samples suitable for Structural Equation Modelling, the finger principle has been observed (Bentler, Yuan, \& Wu, 2010) and use the right sample test per stratum of 10 (Changing Minds, 2012). As shown below, the two cities and seventeen selected municipal police station in Zamboanga del Norte, Region XI are the subject of the study with the total number of 400 respondents. In addition, to determined normal statistics, non-normal statistics, missing statistics, gathering, combinations of populations and model variables (Muthén \& Muthén, 2002).

Inclusion criteria include only the noncommissioned police officers in uniform (men and women) who are on duty and present during the data gathering. Hence, they are the frontline image of the police department whose primary function are in direct contact with the community people. Additionally, only those who are not busy, willing and voluntary to participate would be included 
in the study. Exclusion criteria includes those who are off duty; those who are not free due to their hectic schedules of work; and those who are not willing to participate since they are busy would not be included in the data gathering. Withdrawal criteria include violation of privacy and confidentiality. Likewise instrument not personally answered by the subject respondent of the study or it has only copied from his/ her batch mate shall be withdrawn. In same manner, any item statement which was unanswered or whether intentionally skipped unanswered would be ground for withdrawal.

The following numerical measures used in the computation of data and testing the hypotheses level significance of 0.05 ; the mean was used to determine the level of significance among work engagement, emotional intelligence, safety management and self-esteem; the pearson was utilized to establish the interrelationship between work engagement, emotional intelligence, safety management, and self-esteem; the linear regression was used to determine the significant influence between work engagement, emotional intelligence, self-esteem and safety management and structural equation modeling (SEM) was utilized to explore for best fit model. Factor analysis would carry out in testing the latent variables.

\section{RESULT AND DISCUSSION}

Divulged in Table 1 is the level of emotional intelligence of non-commissioned police officers in Zamboanga del Norte with means ranges from 3.87 to 4.14 with respective overall average of 3.98 or quantitatively depicted is elevated than square root of variance of 0.58 . Statistics results showed that the indicator with the biggest or very high average score was 4.14 - motivating oneself. In addition, managing emotions and empathy are indicators with the lowest average score 3.87 but still labeled as high. Furthermore, the remaining indicators were structured with their corresponding descriptive interpretation from the highest to the lowest average scores. For instance, 4.01 described as high for self-awareness; 4.00 labeled as high for social skill. To facilitate thorough understanding on the facets of emotional intelligence, the details of the indicators of this variable is staged in this section.

The high level of emotional intelligence is an indication that it significantly influences the work engagement of non-commissioned police officers. Accordingly, Sy et al. (2006) noted that employees with high emotional intelligence levels are more capable of controlling feelings that make them feel more confident and in command of their job's task demands. It support the study of Al Ali et al. (2011) which stated that emotional intelligence is essential for employment that require communication with others, inside or outside the organization. This is an actualization of Sinha (2016) which stated that self-awareness significantly to be created for the successful achievement of high performance in work engagement. The higher level of emotional intelligence leads employees to align with the goals and objectives of the organization. In addition, Udoh (2017) which state that the effectiveness in managing emotions means effectiveness in self-leadership which translates to effectiveness in leading people. Inability to manage emotions can be disastrous for both the leader and the people being led and the society.

Table.1: Emotional Intelligence of Non-commissioned Police Officers

\begin{tabular}{|c|c|c|c|}
\hline Indicator & SD & Mean & $\begin{array}{c}\text { Descriptive } \\
\text { Level }\end{array}$ \\
\hline Motivating Oneself & 0.55 & 4.14 & High \\
\hline Self-awareness & 0.56 & 4.01 & High \\
\hline Social Skill & 0.57 & 4.00 & High \\
\hline Empathy & 0.64 & 3.87 & High \\
\hline Managing Emotions & 0.60 & 3.87 & High \\
\hline Overall & 0.58 & 3.98 & High \\
\hline
\end{tabular}

For level of safety management perception of noncommissioned police officers outlined safety management indices, which were organized from the upper level to lowest average score with their corresponding quantitatively depiction and square root of variance. In addition, the indicators were evaluated and deduced in an easy manner to improve the understanding of other investigator. Additionally, the outcome of the inquiry of this independent variable was an average score of 4.12 to 4.35 and the general average received was 4.23 which is described as high with the respective square root of 
variance of 0.51 . The indication safety management among commissioned police officers is always manifested.

The very high level of safety management of noncommissioned police officers affirmed the study of DeBoard (2015) which stated that establishing a safety culture implies that employees are constantly conscious of the risks and dangers in the workplace, including those that they themselves produce. It is inherent in the police profession to observe safety measures at all times. In addition, Grossman (2017) stated that in the field of police, work risk is always a chance, and it is extremely unpredictable, because the potential to become a victim of violent encounters, the need for support from other peers and the lawful use of violence to fulfill the mandate of the police all contribute to a subculture that emphasizes courage, which is eventually linked to perception and action.The very high on safety management of noncommissioned police officers is allied to the contentions of DeBoard (2015) that stated, establishing a safety culture implies that police officers are constantly conscious of the risks and dangers in the workplace.

Table 2: Safety Management of Non-commissioned Police Officers

\begin{tabular}{lccc}
\hline \multicolumn{1}{c}{ Indicator } & SD & Mean & $\begin{array}{c}\text { Descriptive } \\
\text { Level }\end{array}$ \\
\hline Accountability & 0.61 & 4.35 & Very High $\frac{\text { Indigh }}{\text { Procedures }}$ \\
Proning \\
Administration & 0.60 & 4.29 & Very High \\
Employees & 0.55 & 4.23 & Very High \\
Problems & 0.58 & 4.22 & Very High \\
Facilities/equipment/materials & 0.63 & 4.12 & High \\
\multicolumn{1}{c}{$\quad 0.67$} & 4.18 & High \\
& $\mathbf{0 . 5 1}$ & $\mathbf{4 . 2 3}$ & Very High \\
\hline
\end{tabular}

The level of self-esteem of non-commissioned police officers with reference to the three indicators is shown in Table 3 with overall average score of 3.80 or quantitatively depiction and square root of variance. 0.66. The indication self-esteem of non-commissioned police officers is oftentimes manifested. On other hand, the outcome of the statistics the indicator obtained with the highest average score is - performance self-esteem with equivalent total of 4.00 defined as high.In contrary, the indicator with the lowest average score is social self-esteem with equivalent total of 3.64 labeled as high. On the other hand, appearance self-esteem obtained average score of 3.75 labeled as high. In consonance, items involved in the indicator of self-esteem of non-commissioned police officers are presented below.

The high level of self-esteem of noncommissioned police officers is related to the pronouncement of Charles (2008) which implied that there is a need for police agencies to select police applicants who have high self-esteem. Likewise, it conformed to the viewpoint of Bartol and Bartol (2004) and Woody (2005) that it is critical to use psychological screening tests to assess self-esteem and select officers with high self-esteem. Ultimately, Sedikides and Gregg (2003) suggested that selfesteem relates to the perception or subjective assessment of the individual's own self-worth, the emotions of self-respect and self-confidence, and the extent to which the person holds favorable or negative opinions of himself. Selfesteem has something to do with personal views about skills, abilities, and social interactions.

Table 3: Self-esteem of Non-commissioned Police Officers 
4.08 described as high. In contrast, absorption obtained a lowest average score of 3.95 labeled as high.

The high level of work engagement of noncommissioned police officers is allied to the study of Xanthopoulou et al. (2007b) which revealed that engaged employees are highly self-efficacious, optimistic and believe they can satisfy their needs by participating in roles within the organization. The principle of engagement is also relevant to the job of the police. Police officers tend to experience stressful works compare to other occupations due to the nature of their job such as having long working hours of shift, dangerous missions, job rotation or work mobility and unstable workplace assignment.

It has compelling aspects that inspire and motivate members in the organization. Notably, Fleming and Asplund (2007), and Wagner and Harter (2006) pronouncement proved that employees who have continuously shown that they are more productive, lucrative, safer, healthier, and less likely to quit from their organization. Info, Xanthopoulou et al. (2007b) revealed that engaged employees are highly self-efficacious, optimistic and believe they can satisfy their needs by participating in roles within the organization.

Table 4: Level of Work Engagement of Non-commissioned Police Officers

\begin{tabular}{lcccc}
\hline & Indicator & SD & Mean & Descriptive Level \\
\hline Dedication & & 0.55 & 4.35 & Very High \\
Vigor & 0.58 & 4.08 & High \\
Absorption & & 0.65 & 3.95 & High \\
& Overall & $\mathbf{0 . 5 3}$ & $\mathbf{4 . 1 3}$ & High \\
\hline
\end{tabular}

The Table 5.1 presents the test of significance relationship among emotional intelligence with work engagement registered a computed r-value of .704 with $\mathrm{p}$ value which is equal to .000 . On other hand, finding disclosed that $\mathrm{p}$-value is lower than 0.05 it means that emotional intelligence was highly and significantly correlated with work engagement in non-commissioned police officers. It implies that the increase in emotional intelligence corresponds to highly increase with work engagement.

Analyzing further, self-awareness is correlated to: vigor registered a computed r-value of .470 with p-value which is to .000 (Significant); dedication registered a computed r-value is .489 with p-value which is equal to .000 (Significant); absorption registered a computed $\mathrm{r}$-value of .608 with p-value which is to .000 (Significant).The overall results on the correlation between self-awareness and vigor of work engagement obtained registered computed r-value of .641 with p-value which is equal to .000 (Significant). In addition, managing emotions is correlated to: vigor registered a computed r-value of .487 with p-value which is equal to .000 (Significant); dedication registered a computed r-value of .362 with p-value which is equal to .000
(Significant); absorption registered a computed r-value of .616 with p-value which is equal to .000 (Significant). The overall results on the correlation between managing emotions and work engagement obtained registered computed r-value of .608 with p-value which is equal to .000 (Significant).

Likewise, motivating oneself is correlated to: vigor registered a computed r-value of .482 with p-value which is equal to .000 (Significant); dedication registered a computed r-value of .571 with p-value which is equal to .000 (Significant); absorption registered a computed r-value of .543 with p-value which is equal to .000 (Significant). The overall results on the correlation between motivating oneself and work engagement obtained registered computed r-value of .648 with p-value which is equal to .000 (Significant).

In the same way, empathy is correlated to: vigor registered a computed r-value of .524 with p-value which is equal to .000 (Significant); dedication registered computed $\mathrm{r}$ value of .389 with $\mathrm{p}$-value which is equal to .000 (Significant); absorption registered computed r-value of .574 with p-value which is equal to .000 (Significant). The overall results on the correlation between empathy and work 
engagement obtained registered computed r-value of .617 with p-value which isequal to .000 (Significant).

Moreover, social skill is correlated to: vigor registered computed r-value of .416 with p-value which is equal to .000 (Significant); dedication registered computed $\mathrm{r}$ value of .467 with p-value which is equal to .000
(Significant); absorption registered computed r-value of .461 with p-value which is equal to .000 (Significant). The overall results on the correlation between social skill and work engagement obtained registered computed r-value of .548 with p-value which is to .0000 (Significant).

Table 5.1: Significance on the Relationship between Emotional Intelligence and Work Engagement of Non-commissioned Police Officers

\begin{tabular}{|c|c|c|c|c|}
\hline \multirow{2}{*}{$\begin{array}{c}\text { Emotional } \\
\text { Intelligence }\end{array}$} & \multicolumn{4}{|c|}{ Work Engagement } \\
\hline & Vigor & Dedication & Absorption & Overall \\
\hline \multirow{2}{*}{ Self-awareness } & $.470 * *$ & $.489 * *$ & $.608 * *$ & $.641 * *$ \\
\hline & $(.000)$ & $(.000)$ & $(.000)$ & $(.000)$ \\
\hline \multirow{2}{*}{ Managing Emotions } & $.487 * *$ & $.362 * *$ & $.616^{* *}$ & $.608 * *$ \\
\hline & $(.000)$ & $(.000)$ & $(.000)$ & $(.000)$ \\
\hline \multirow{2}{*}{ Motivating Oneself } & $.482 * *$ & $.571 * *$ & $.543 * *$ & $.648 * *$ \\
\hline & $(.000)$ & $(.000)$ & $(.000)$ & $(.000)$ \\
\hline \multirow{2}{*}{ Empathy } & $.524 * *$ & $.389 * *$ & $.574 * *$ & $.617 * *$ \\
\hline & $(.000)$ & $(.000)$ & $(.000)$ & $(.000)$ \\
\hline \multirow{2}{*}{ Social Skill } & $.417 * *$ & $.467 * *$ & $.461 * *$ & $.548 * *$ \\
\hline & $(.000)$ & $(.000)$ & $(.000)$ & $(.000)$ \\
\hline \multirow{2}{*}{ Overall } & $.555 * *$ & $.495 * *$ & $.659 * *$ & $.704 * *$ \\
\hline & $(.000)$ & $(.000)$ & $(.000)$ & $(.000)$ \\
\hline
\end{tabular}

The findings support the study of Benson et al. (2012), Koman and Wolff (2008), Momeni (2009), Polychroniou (2009), Singh (2013a), Singh (2013b) which stated that leaders who exhibited emotional intelligence has significant effect on subordinate work engagement. Work engagement is significantly associated with emotional intelligence and positive impact on most elements of work engagement. It was expected to a police officer with a strong emotional intelligence is positively high in work engagement.

Shown in Table 5.2. The test of significance relationship between safety management and work engagement of non-commissioned police officers registered overall computed $r$-value of .561 with $p$-value which is equal to .000 . On other hand, findings divulged that $\mathrm{p}$-value is smaller than 0.05. It means that there is an importance connection between safety management with work engagement in non-commissioned police officers. The indication safety management has moderate correlation with work engagement. The finding signifies that in every increase of safety management moderately increases work engagement of non-commissioned police officers.

Presenting the detail of the data, administration is correlated to: vigor registered a computed r-value of .082 with p-value which is equal .000 (Significant); dedication registered computed $\mathrm{r}$-value of .533 with $\mathrm{p}$-value which is

equal to .000 (Significant); and absorption registered a computed r-value of. 415 with $\mathrm{p}$ - value which is equal to .000 (Significant). The overall results on the correlation between administration and work engagement obtained registered computed r-value of .535 with p-value which is equal to .000 (Significant).

In the same view, accountability is correlated to: vigor registered a computed r-value of .295 with p-value which is equal to .000 (Significant); dedication registered a 
computed r-value of .434 with p-value which is equal to .000 (Significant); and absorption registered a computed r-value of .327 with p-value which is equal to .000 (Significant).The overall results on the correlation between accountability and work engagement obtained registered computed r-value of .424 with p-value which is equal to .000 (Significant).

On the other hand, facilities/equipment/materials is correlated to: vigor registered a computed r-value of .385 with p-value which is equal to .000 (Significant); dedication registered computed r-value of .425 with p-value which is equal to .000 (Significant); and absorption registered a computed r-value which is equal to .383 with .000 (Significant). The overall results on the correlation between facilities/equipment/materials obtained registered computed r-value of .486 with p-value which is equal to .000 (Significant).

Similarly, procedure is correlated to: vigor registered a computed r-value of .289 with p-value which is equal to .000 (Significant); dedication registered a computed r-value of .473 with $\mathrm{p}$-value which is equal to .000 (Significant); and absorption registered a computed $\mathrm{r}$-value of .292 with p-value which is to .000 (Significant). The overall results on the correlation between procedures and work engagement obtained a registered computed $r$-value of .420 with p-value which is equal to .000 (Significant).

Nonetheless, problems are correlated to: vigor registered a computed r-value of .328 with p-value which is equal to .000 (Significant); dedication registered a computed r-value is .465 with p-value of .000 (Significant); and absorption registered a computed r-value of.369 with p-value which is equal to .000 (Significant). The overall results on the correlation between problems and work engagement achieved a registered computed r-value of .468 with p-value which is equal to .000 (Significant).

When employees are correlated to: vigor, it registered a computed r-value of .373 with p-value which is equal to .000 (Significant); dedication registered a computed r-value of .488 with p-value which equal to .000 (Significant); and absorption registered a computed $\mathrm{r}$-value of.431 with p-value which is equal to .000 (Significant).The overall results on the correlation between employees and work engagement obtained a registered computed r-value of .468 with p-value which is equal to .000 (Significant).

Table 5.2: Significance on the Relationship between Safety Management and Work Engagement of Non-commissioned Police Officers

\begin{tabular}{|c|c|c|c|c|}
\hline \multirow{2}{*}{$\begin{array}{c}\text { Safety } \\
\text { Management }\end{array}$} & \multicolumn{4}{|c|}{ Work Engagement } \\
\hline & Vigor & Dedication & Absorption & Overall \\
\hline \multirow{2}{*}{ Administration } & $.382 * *$ & $.533 * *$ & $.415^{* *}$ & $.535^{* *}$ \\
\hline & $(.000)$ & $(.000)$ & $(.000)$ & $(.000)$ \\
\hline \multirow{2}{*}{ Accountability } & $.295 * *$ & $.434 * *$ & $.327 * *$ & $.424 * *$ \\
\hline & $(.000)$ & $(.000)$ & $(.000)$ & $(.000)$ \\
\hline \multirow{2}{*}{$\begin{array}{l}\text { Facilities/ } \\
\text { Equipment/ } \\
\text { Materials }\end{array}$} & $.385^{* *}$ & $.425 * *$ & $.383 * *$ & $.486^{* *}$ \\
\hline & $(.000)$ & $(.000)$ & $(.000)$ & $(.000)$ \\
\hline \multirow{2}{*}{ Procedures } & $.289 * *$ & $.473 * *$ & $.292 * *$ & $.420 * *$ \\
\hline & $(.000)$ & $(.000)$ & $(.000)$ & $(.000)$ \\
\hline \multirow{2}{*}{ Problems } & $.328 * *$ & $.465 * *$ & $.369 * *$ & $.468 * *$ \\
\hline & $(.000)$ & $(.000)$ & $(.000)$ & $(.000)$ \\
\hline
\end{tabular}




$\begin{array}{lllll} & .373 * * & .488^{* *} & .431^{* *} & .523 * * \\ & (.000) & (.000) & (.000) & (.000) \\ \text { Overall } & \mathbf{. 4 0 3 * *} & \mathbf{. 5 5 3 * *} & \mathbf{. 4 3 5 * *} & \mathbf{. 5 6 1 * *} \\ & \mathbf{( . 0 0 0 )} & \mathbf{( . 0 0 0 )} & \mathbf{( . 0 0 0 )} & \mathbf{( . 0 0 0 )}\end{array}$

This support the proposition described by Sheahan (2017) that safety management is a feature that enhances the efficiency of the business by anticipating operational, procedural or environmental hazards and threats before they happen. It is also aligned the pronouncement of Aksorn and Hadikusumo (2008) which illustrated the safety management practices is the most effective way in reducing the number of unsafe conditions.

Table 5.3 mentioned the test of significance relationship among self-esteem and work engagement of non-commissioned police officers registered overall computed r-value of .159 with p-value which is equal to .000 . It means that self-esteem was negligible and significantly correlated with work engagement. It implies that the increase of self-esteem corresponds to a negligible increase in work engagement of non-commissioned police officers.

Articulating the details of the data, performance is correlated to: vigor registered a computed r-value of .315 with p-value which is equal to .000 (significant); dedication registered a computed r-value of .363 with p-value which

is equal to .000 (significant); absorption registered a computed r-value of .426 with p-value which is equal to .000 (significant). The overall results on the correlation between performance and work engagement of non-commissioned police officers registered a computed r-value of .450 with pvalue which is equal to .000 (significant).

Consequently, social is correlated to: vigor registered a computed r-valueof .083 with p-value which is equal to .098 (non-significant); dedication registereda computed r-value of .023 with p-value which is equal to .643 (non-significant); absorption registered a computed r-value of .143 with p-value which is equal to .004 (significant). The overall results on the correlation between social self-esteem and work engagement of non-commissioned police officers obtained registered a computed r-value of .106 with p-value which is equal to .035 (significant).

Furthermore, appearance self-esteem is correlated to: vigor registered a computed r-value of -.059 with p-value which is equal to .241 (non-significant); dedication registered a computed r-value of .008 with p-value which is equal to .878 (non-significant); absorption registered a computed r-value of -.012 with p-value which is equal to .805 (non-significant). The overall results on the correlation between appearance self-esteem and work engagement of non-commissionedpolice officers obtained registered a computed r-value of -.030 with $\mathrm{p}$-value which is equal to .544 (non-significant).

Table 5.3: Significance on the Relationship between Self-esteem and Work Engagement of Non-commissioned Police Officers

\begin{tabular}{lcccc}
\hline \multirow{2}{*}{ Self-esteem } & \multicolumn{4}{c}{ Work Engagement } \\
\cline { 2 - 4 } & Vigor & Dedication & Absorption & Overall \\
\hline \multirow{3}{*}{ Performance } & $.315^{* *}$ & $.363^{* *}$ & $.426^{* *}$ & $.450^{* *}$ \\
& $(.000)$ & $(.000)$ & $(.000)$ & $(.000)$ \\
& & & & $.106^{*}$ \\
Social & .083 & .023 & $.143^{* *}$ & $(.035)$
\end{tabular}




$\begin{array}{rcccc}\text { Appearance } & -.059 & .008 & -.012 & -.030 \\ & (.241) & (.878) & (.807) & (.544) \\ \text { Overall } & \mathbf{. 0 9 8} & \mathbf{. 1 1 9 *} & \mathbf{. 1 6}^{* * *} & \mathbf{. 1 5 9 * *} \\ & \mathbf{( . 0 5 1 )} & \mathbf{( . 0 1 7 )} & \mathbf{( . 0 0 0 )} & \mathbf{( . 0 0 1 )}\end{array}$

On the other hand, the relationship between selfesteem and work engagement of non-commissioned police officers signified that self-esteem provides significant bearing on work engagement. The findings are evidenced that back-up the pronouncement of Pierce (2004) which stated that self-esteem is a private assessment that reflects what people believe of themselves as individuals.It runs parallel on the statement of Adler and Stewart (2004) that self-esteem measures of how much a person values, approves, appreciates, awards, or likes him or herself.

Thus, the high self-esteem result confirmed the study of Baumeister et al. (2003) that people with strong selfesteem are more likely to continue in the face of hard assignments than low self-esteem.Employees would have a high level of commitment to work when they see themselves as valued skilled employees of their organizations Rotich (2016). It is implied that work engagement of a police officer increases as self-esteem will progress to higher levels. In like manner, the higher self-esteem the more probable that a noncommissioned police officer would be creative at work and more likelihood of achievement Torrie (2017).

Table 6 is the test of significant influence among emotional intelligence with work engagement of noncommissioned police officers registered a computed F-value of 160.344 , r-value of .741 , adjusted $\mathrm{r}^{2}$ of .548 with $\mathrm{p}$-value which is equal to .000 It indicated that that the level of significance is lower than 0.05 . It implies that emotional intelligence, safety management and self-esteem, are predictors of job work engagement.

Table 6: Significance on the Influence of the Exogenous Variables on the Work Engagement of Non-commissioned Police Officers

\begin{tabular}{|c|c|c|c|c|c|}
\hline \multicolumn{6}{|c|}{ Work Engagement } \\
\hline Exogenous Variables & & $B$ & $\mathrm{~B}$ & $t$ & Sig. \\
\hline Emotional Intelligence & & .892 & .687 & 14.293 & .000 \\
\hline Safety Management & & .176 & .172 & 3.931 & .000 \\
\hline Self-esteem & & -.157 & -.197 & -5.146 & .000 \\
\hline $\mathrm{R}$ & .741 & & & & \\
\hline $\mathrm{R}^{2}$ & .548 & & & & \\
\hline $\mathrm{F}$ & 160.344 & & & & \\
\hline$\rho$ & .000 & & & & \\
\hline
\end{tabular}

The significance on the influence of the variables to work engagement revealed that emotional intelligence is predictor of work engagement of non-commissioned police officers particularly on the indicators on social skill, empathy, motivating oneself, managing oneself and selfawareness influences job satisfaction. On the other hand, 
safety management is a good predictor of work engagement specifically on facilities/equipment/materials, accountability, administration, procedures, problems and employees.

Evidently, results confirm previous studies indicating that emotional intelligence is positively linked with work engagement in professionals. Workers with high emotional intelligence appear to be more active and energetic at work, to report higher excitement, inspiration, pride and work-related challenges, and to show greater concentration and energy during work activities.

In like manner, findings runs parallel to the pronouncement of Baumeister et al. (2003) that self-esteem plays an important role in motivation and success of individuals' life where people with high self-esteem are more willing than others to choose their own strategies. They are more responsive to situational cues indicating when to persist and when to move on to a more promising alternative. Moreover, it support to the statement of Stotland (2016) that statespolice officers high self-esteem is more skilled to work in challenging circumstances and is less susceptible to stress issues. Improving self-esteem will also enhance the efficiency of the police officer.

Furthermore, the very high level of significant of safety management objectively reinforces the primary function of the police officer as law enforcer and protector of life and property. It support to the pronouncement of Aksorn and Hadikusumo (2008) which states that safety management practices, were the most efficient way to reduce the amount of unsafe circumstances.

\section{Establishing the Best Structural Model}

This section highlights the analysis on the interrelationships among emotional intelligence, self-esteem and safety management with work engagement among noncommissioned police officers particularly in the Province of Zamboanga del Norte. There are four alternative models tested to achieve the best fit model of work engagement of non-commissioned police officers. Each model has a framework that could be decomposed into measurement model

and structural model. The structural model represents a measure loads on each factor to their latent constructs that defines relations among the latent factors.

Moreover, assessment of fit was used as baseline for accepting and rejecting the model. As a rule, the researcher establishes the relationship of the latent variable toward the different latent variables. Furthermore, it institutes the relationship between endogenous and exogenous variables. The moment that structured model exhibits with suitable fit, it underscores that there is consistency of the empirical relationships among variables inferred by the model. The model parameter estimates entail the magnitude and direction of the relationships among variables.

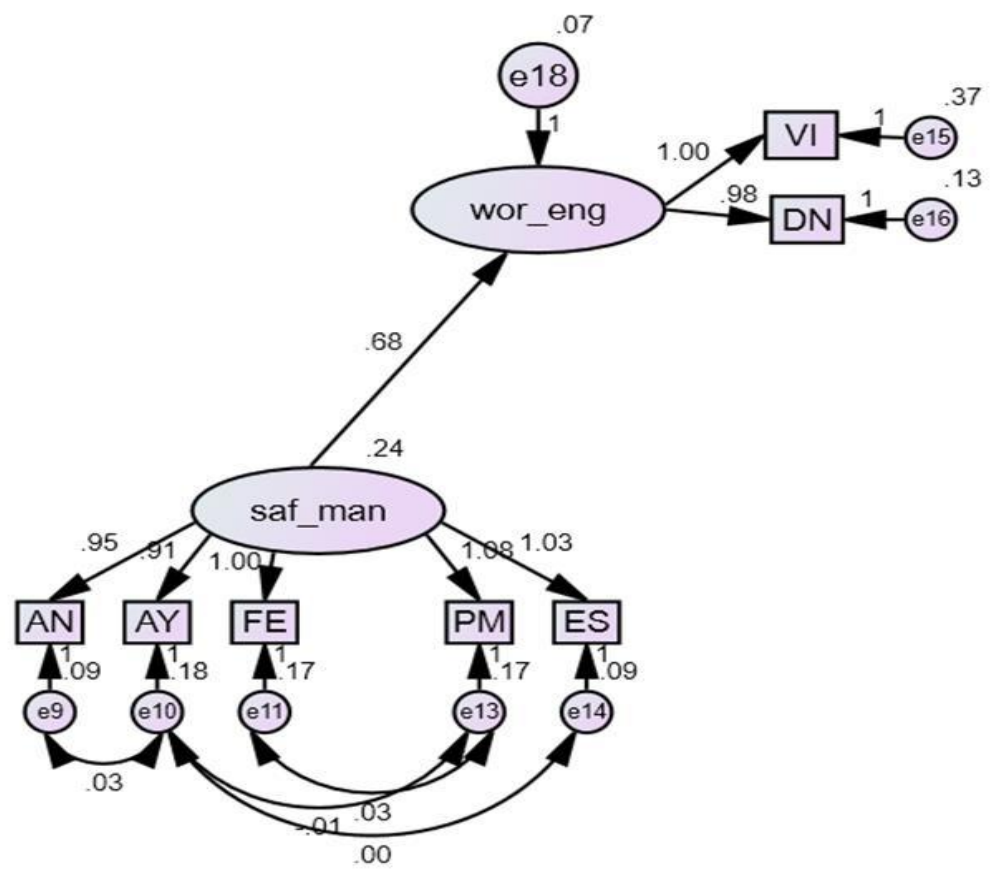

Fig.1: The Best Fit Model for Work Engagement 


\section{Legend:}

wor_eng - work engagement

$\mathrm{VI}-$ Vision

DN - Dedication

saf_man - safety management

AN - Administration

\author{
AY - Accountability \\ FE - Facilities/Equipment/Materials \\ PM - Problems \\ ES - Employees
}

Distinguishing of best fit model, all of indices included must consistently fall within acceptable ranges. Chi-square/degrees of freedom value must be less than 2 with registered computed p-value greater or which is equal to 0.05. Root average Square of Error Approximation value lower than tested significance level of 0.05 and its corresponding p-close value must be greater or equal to 0.05 . The other indices such a NFI, TLI, Comparative Fit Index with Goodness of Fit must be all higher of 0.90 .

Table 7: Goodness of Fit Measures Generated Best Fit Model.

\begin{tabular}{|c|c|c|}
\hline INDEX & CRITERION & MODEL FIT \\
\hline P-value & $>0.05$ & $\begin{array}{l}\text { VALUE } \\
.229\end{array}$ \\
\hline CMIN/DF & $0<$ value $<2$ & 1.304 \\
\hline GFI & $>0.95$ & .992 \\
\hline CFI & $>0.95$ & .998 \\
\hline NFI & $>0.95$ & .992 \\
\hline TLI & $>0.95$ & .996 \\
\hline RMSEA & $<0.05$ & .028 \\
\hline P-Close & $>0.05$ & .796 \\
\hline
\end{tabular}

Legend:

CMIN/DF - Chi Square/Degrees of Freedom

GFI - Goodness of Fit Index

CFI - Comparative Fit Index

NFI - Normed Fit Index

TLI - Tucker- Lewis Index

RMSEA - Root Mean Square of Error Approximation

The generated best fit model found to have indices that shows a very good fit to the data as indicated by $\mathrm{CMIN} / \mathrm{DF}=1.304, \mathrm{RMSEA}=.02 / 8, \mathrm{p}$-close $=.796$ and indices such as NFI (.992), TLI (.996), CFI (.998) and GFI (.992). All of the indices with their corresponding values were greater than 0.90 or meet the requirements of goodness of fit measures.

Since, generated model is a good fit model of work engagement, this does not warrant for further testing to any models. It is therefore stated that the tested significance level is higher of 0.05 . It means that there is model that best fit on work engagement non-commissioned police officers of Zamboangadel Norte. The model clearly demonstrates the organization of safety management as predictors of work engagement.

Moreover, the assessment of fit was used as baseline for accepting and rejecting the model. Based on the findings, the model evidently illuminates the essentials of safety management as predictors of work engagement. Safety management is an important component to government officials to appropriately manage organizational resources in achieving the mission and goals of the organization. Hence, the findings highlighted that work engagement of noncommissioned police officers must be anchored on safety management particularly on facilities, accountability, administration, problems and employees.

Work engagement is significantly associated with safety management, facilities/equipment/materials, accountability, administration, procedures, problems and ositive influence on most tpparently, it explores the and Storm (2003) that lem-focused.

\section{NCES}

[1] ACHIM, A.C. (2018). Particularities of occupational health and safety management in the police environment. Proceedings of the International Conference on Business Excellence, 12(1), 1-9. https://doi.org/10.2478/picbe-20180002 
[2] Adler, N., \& Stewart, J. (2004). What is self-esteem? A psychologist explains [Blog post]. Retrieved from https://positivepsychology.com/self-esteem/

[3] Agolla, J. (2009). Occupational stress among police officers: the case of Botswana police service. Research Journal of Business Management, 3(1), 25-35. doi: 10.3923/rjbm.2009.25.35

[4] Aksorn, T., \& Hadikusumo, B.H. (2008). Measuring effectiveness of safety programmes in the thai construction industry. Construction Management and Economics, 26(4), 409-421.doi: 10.1080/01446190801918722

[5] Al Ali, O., Garner, I., \&Magadley, W. (2011).An Exploration of the relationship between emotional intelligence and job performance in police organizations. Journal of Police and Criminal Psychology, 27, 1-9. doi: 10.1007/s11896-011-90889.

[6] Aremu, A., \& Tejumola, T. (2008).Assessment of emotional intelligence among Nigerian police. Journal of Social Sciences, 16(3), 221-226, doi: 10.1080/09718923.2008.11892622

[7] Avolio, B. J., Gardner, W., Walumbwa, F. O., Luthans, F., \& May, D. R. (2004). Unlocking the mask: A look at the process by which authentic leaders' impact follower attitudes and behaviors.The Leadership Quarterly 15(6), 801-823. doi 10.1016/j.leaqua.2004.09.003

[8] Bacon, T. (2016). Emotion regulation: Managing emotions. Retrieved form https://www.moodcafe.co.uk/media/15343/ER_handout_Final _16_June_2016\%20pdf.pdf

[9] Bakker, A. B., \& Demerouti, E. (2007). The job demandsresources model: State of the art. Journal of Managerial Psychology, 22(3), 309-328. doi: 10.1108/02683940710733115

[10] Bakker, A., \& Demerouti, E. (2008), "Towards a model of work engagement", Career Development International, 13(3), 209-223.https://doi.org/10.1108/13620430810870476

[11] Bakker, A. B., Schaufeli, W. B., Leiter, M. P., \&Taris, T. W. (2008). Work engagement: An emerging concept in occupational health psychology. Work \& Stress, 22(3), 187200. doi: 10.1080/02678370802393649

[12] Bartol, C. R., \&Bartol, A. M. (2004).Introduction to forensic psychology. Thousand Oaks, California U.S.A.: Sage Publication. Retrieved from:

https://www.abebooks.co.uk/book-search/title/introduction-toforensic-psychology/author/bartol-anne-m-bartol-curt-r/

[13] Basinska, B. A., \& Dåderman, A. M. (2019). Work values of police officers and their relationship with job burnout and work engagement. Frontiers in Psychology, 10, 442.doi: 10.3389/fpsyg.2019.00442

[14] Baumeister, R. F., Campbell, J. D., Krueger, J. I., \&Vohs, K. D. (2003). Does high self-esteem cause better performance, interpersonal success, happiness, or healthier lifestyles? SAGE Journals, 4(1) 1-44. doi.org/10.1111/1529-1006.01431
[15] Benson, J., Zigarmi, D., \& Nimon, K. (2012).Manager's emotional intelligence, their perceived use of directive and supportive leader behaviors and resultant employee satisfaction. Journal of Business Administration Research, 1(2), 30-50. doi:10.5430/jbar.v1n2p30

[16] Bentler, M., Yuan, K., \& Wu, R. (2010).'Ridge structural equation modelling with correlation matrices for ordinal and continuous data'.British Journal of Mathematical and Statistical Psychology, 64, 107-133

[17] Blumenstein, L., Fridell, L., \& Jones, S. (2012). The link between traditional police sub-culture and police intimate partner violence. Policing An International Journal of Police Strategies \& Management, 35(1), 147-164.

[18] Budihardjo, S. A. (2015). Knowledge management support, employee engagement, knowledge sharing and corporate performance. Annual International Conference on Business Strategy \& Organization, 24-30

[19] Cavill, S., \&Sohail, M. (2007).Accountability arrangements to combat corruption.http://unpan1.un.org/intradoc/groups/public/docum ents/un-dpadm/unpan043877.pdf

[20] Changing Minds.(2012). Changing minds and perceptions. Social Research. Retrieved from http: www.changingminds.org.

[21] Charles, S. (2008). Exploring police integrity: Professional integrity, modern racism, self-esteem, and universalitydiversity orientation of police officers in a large urban police agency. https://doi.org/10.1007/978-3-030-29065-8

[22] Cherry, K. (2018).5 Components of emotional intelligence. Very well mind. Retrieved from https://www.verywellmind.com/components-of-emotionalintelligence-2795438

[23] Chokprachakchat, S. (2011).Guidelines for the royal thai police's human resource management. The Secretariat of the Senate, Bangkok, Thailand.

[24] Coleman, A. (2008). A dictionary of psychology (3 ed.). Oxford University Press. ISBN 9780199534067.

[25] Conroy, R. (2018).Emotional intelligence and law enforcement: $A$ case for change.https://www.lawenforcementtoday.com/emotionalintelligence-law-enforcement-case-change/.

[26] Crum II, J. E. (2017). Controlling your emotions. The role of executive function in emotion regulation. [Blog post] https://www.psychologytoday.com/

[27] DeBoard, M. A. (2015). Applying systems thinking to law enforcement safety: Recommendation for a comprehensive safety management framework. https://www.hsdl.org/?view\&did=790320

[28] Deshwal, S. (2015).Impact of emotional intelligence on employee engagement. International Journal of Multidisciplinary Research and Development, 2, 255-256. 
[29] Dhani, P., \& Sharma, T. (2016).Emotional intelligence; History, models and measures. International Journal of Science Technology \& Management, 5, 189-201.

[30] Ellrich, K. (2016). Violent victimization, professional selfesteem, and punitivity of german police officers. Policing and Society, 1-19. 10.1080/10439463.2016.1262363.

[31] Fernández-Muñiz, B., Montes-Peón, J.M., \&VázquezOrdáz,C.J. (2009). Relation between occupational safety management and firm performance. Safety Science, 47, 980991.

[32] Fleming, J. H., \&Asplund, J. (2007).Human sigma. New York: Gallup press.

[33] Grant, R. W., \&Keohane, R. O. (2005).Accountability and abuses of power in world politics.American Political Science Review 99(1), 29-43.

[34] Grossman, D. (2017). The police culture and work stress. Newbury Park, California. Sage Publishing. Retrieved from: https://us.sagepub.com/sites/default/files/upmbinaries/77481_cox_ch_8.pdf

[35] Hakanen, J. J., \&Schaufeli, W. B. (2012). Do burnout and work engagement predict depressive symptoms and life satisfaction? A three-wave seven-year prospective study.Journal of Affective Disorders, 141, 415-424.

[36] Hannah, S., Avolio, B., \&Walumbwa, F.(2011). Relationships between authentic leadership, moral courage, and ethical and pro-social behaviors.Business Ethics Quarterly, 2(4), 555-578.

[37] Harvard Business Review Analytic Services. (2013). The impact of employee engagement on performance. Retrieved from:

https://hbr.org/resources/pdfs/comm/achievers/hbr_achievers_r eport_sep13.pdf

[38] Igbinovia, M. O. (2016). Emotional self-awareness and information literacy competence as correlates of task performance of academic library personnel.Library Philosophy and Practice (ejournal).http://digitalcommons.unl.edu/libphilprac/1370

[39] Javidi, M., \& Ellis, B. (2016).Capturing the moment: CounterVUCA leadership for 21st century policing.Law Enforcement Today.Retrieved from https://www.lawenforcementtoday.com/capturing-themoment-counter-vuca-leadership-for-21st-century-policing/.

[40] Kernis, M. H. (2003). Toward a conceptualization of optimal self-esteem. Psychological Inquiry, 14(1), 1-26.

[41] Khotami, M. (2017). The concept of accountability in good governance. Advances in Social Science, Education and Humanities Research.https://doi.org/10.2991/icodag-17.2017.6

[42] Koman, E. S., \& Wolff, S. B. (2008). Emotional intelligence competencies in the team and team leader: A multi-level examination of the impact of emotional intelligence on team performance. Journal of Management Development, 27(1), 5575.

[43] Law, K.S., Wong, C.S., \& Song, L.J. (2004).The construct and criterion validity of emotional intelligence and its potential utility for management studies. Journal of Applied Psychology, 89, 483-496.

[44] Lomax, R., \& Li, J. (2013).Correlational research. Retrieved from htt://www.education.com/reference/article/correlationalresearch/.

[45] Lynch, R.G., \& Lynch S.R. (2005). The police manager. $\left(6^{\text {th }}\right.$ edition).Mattew Bender \& Company, Inc.

[46] McDonald, R. P., \& Ho, M-H, R. (2002). Principles and practice in reporting structural equation analyses. Psychological Methods, 7(1), 64-82

[47] Mearns, K., Whitaker, S. M., \&Flin, R. (2003).Safety climate, safety management practice and safety performance in offshore environments. Safety Science, 41, 641-680. doi:10.1016/S0925-7535(02)00011-5.

[48] Misnan, M. S., \& Mohammed, A. H. (2007). Development of safety culture in the construction industry: A conceptual framework. Association of Researchers in Construction Management, 13-22.

[49] Momeni, N. (2009). The relation between managers' emotional intelligence and the organizational climate they create. Public Personnel Management, 38(2), 35-48. Retrieved from http://www.ipma-hr.org/node/21487

[50] Monier, H. (2014). Emotion Management at Work: The Case of Elite Policemen. Home and Enterprise, 4(3), 105-121. https://www.cairn.info/revue-rimhe-2014-4-page-105.htm

[51] Mostert, K. (2006). Job resources, work engagement and the mediating role of positive work-home interaction of police officers in the North West province. ActaCriminologica, 19(3), 64-87. umu.diva-portal.org > smash $>$ record

[52] Murphy, C., Stosny, S., \&Morrel, T. (2005). Change in selfesteem and physical aggression during treatment for partner violent men. Journal of family Violence 20, 201210.10.1007/s10896-005-5983-0.

[53] Muthén, L. K., \&Muthén, B. O. (2002).How to use a Monte Carlo study to decide on sample and determine power.Structural Equation Modeling: A MultidisciplinaryJournal,9(4).https://doi.org/10.1207/S153280 07SEM0904_8

[54] Nelson, D. B., \& Low, G. R. (2011). Emotional intelligence: Achieving academic and career excellence (2nd ed.). Boston: Prentice Hall.

[55] Olivier, A.L., \&Rothmann, S. (2007). Antecedents of work engagement in a multinational oil company, SA Journal of Industrial Psychology, 33(3), 49-56.

[56] Panes, R. T., Gempes, G. P., \&Genuba, R. L.(2017). A causal model on job satisfaction among the teaching force of selected private schools in region xi. International Journal of Scientific $\begin{array}{llll}\text { \& Technology } & \text { Research, 6(09), }\end{array}$ https://pdfs.semanticscholar.org/18d2/1ac0d8e41f6f12a581873 ccb96d6afaf2d31.pdf

[57] Pierce, J., \& Gardner, D. (2004). Self-esteem within the work and organizational context: A review of the organization-based 
self-esteem literature. Journal of Management, 30(5), 591-622. DOI:10.1016/j.jm.2003.10.001.

[58] Polychroniou, P.V. (2009). Relationship between emotional intelligence and transformational leadership of supervisors: the impact on team effectiveness. Team Performance Management, 15(7/8), 343-356. https://doi.org/10.1108/13527590911002122

[59] Rhaffor, K., Saparuddin, \& Maidin, (2014). Employees' perception towards safety and health practices in a small-sized organization. Retrieved from https://www.researchgate.net/publication/322383713

[60] Rothmann, S., \& Storm, K. (2003).Work engagement in the South African police service. European Congress of Work and Organizational Psychology, 14-17.

[61] Rotich, R. K. (2016). The impact of organizational-based selfesteem on work engagement among state corporations employees in Kenya. European Journal of Business and Management, 8(15), 1-11.

[62] Schaufeli, W. B., Salanova, M., Gonzáles-Romá, V., \& Bakker, A.B. (2002). The measurement of engagement and burnout: A two sample confirmatory factor analytic approach. The Journal of Happiness Studies, 3 (1), 71-92. doi: 10.1023/A:1015630930326

[63] Scherer, K. R., Schorr, A., \&Johnstone, T. (2001).Appraisal processes in emotion: Theory, methods, research. Oxford: Oxford University Press.

[64] Schutte, N., Toppinen, S., Kalimo, R., \& Schaufeli, W.B. (2000). The factorial validity of the maslach burnout inventorygeneral survey (MBI-GS) across occupational groups and nations.Journal of Occupational and Organizational Psychology, 73, 53-66.

[65] Sedikides, C., \& Gregg, A. (2003).Portraits of the self.The SAGE Handbook of Social Psychology: Concise student edition.

DOI: 10.4135/9781848608221.n5.https://sk.sagepub.com > reference > hdbk_socpsych > n5

[66] Shaikh, M., \&Kapadi, P. (2014). Occupational stress, burnout and coping in police personnel: Findings from a systematic review. American International Journal of Research in Humanities, Arts and Social Sciences, 6(2), 144-148. https://www.researchgate.net > publication

[67] Sheahan, K. (2017). What is safety management?https://bizfluent.com/about-6503265-SafetyManagement-.html

[68] Singh, P. (2013a). Influence of leaders' intrapersonal competencies on employee job satisfaction. International Business and Economics Research Journal, 12(10), 12891302. Retrieved from http://journals.cluteonline.com/index.php/IBER/article/view/81 $37 / 8187$

[69] Singh, P. (2013b). Influence of the leaders' emotionally intelligent behaviors on their employees' job satisfaction. International Business and EconomicsResearch Journal,12(7),
$799-814$.

Retrieved

from

http://journals.cluteonline.com/index.php/IBER/article/view/ $7969 / 8023$

[70] Sinha, D. (2016). Study of emotional intelligence amongst the employees of service sector.International Journal of Global Management, 6, 32-40.

[71] Staff, P. (2013). What is accountability? https://www.payh.org/what-is-accountability/

[72] Stolzer, A., Halford, C., \&Goglia, J. (2008).Safety management systems in aviation.Farnham, Surrey, England: Ashgate Publishing Limited.

[73] Stotland, E. (2016). Self-esteem and stress in police work. National Institute for Occupational Safety and Health, 76-187. https://www.cdc.gov > niosh > nioshtic-2

[74] Sy, T., Susanna, T., \& O'Hara, L. A. (2006).Relation of employee and manager emotional intelligence to job satisfaction and performance. Journal of Vocational Behavior, 68, 461-473. doi:10.1016/j.jvb.2005.10.003

[75] Torrie, W. (2017).How your self-esteem affects your performance at work. https://www.acegoals.com/self-esteemaffects-performance-work/

[76] Udoh, U. (2017). Managing your emotions. https://www.researchgate.net

/publication/319549904_Managing_your_emotions/citation/do wnloadUniversity of Kansas.

[77] Valtteri, K., (2014). Fostering work engagement through dedication: Case ramboll.http://tampub.uta.fi/bitstream/handle/10024/95870/GR ADU-1404213426.pdf; sequence $=1$

[78] Wachter, J. K., \&Yorio, P. L. (2014). A system of safety management practices and worker engagement for reducing and preventing accidents: An empirical and theoretical investigation.Accident Analysis \& Prevention. 68, 117130.https://doi.org/10.1016/j.aap.2013.07.029

[79] Waggoner, L. B. (2012). Police officer fatigue: the effects of consecutive night shift work on police officer performance. Electronic Dissertations and Theses - Criminal Justice.http://hdl.handle.net/2376/4273

[80] Wagner, R., \& Harter, J. (2006). 12: The elements of great managing. Washington, D.C: The Gallup organization.

[81] Woody, R. H. (2005). The police culture: Research implications for psychological services. Professional Psychology: Research and Practice, 36(5), 525-529.

[82] Xanthopoulou, D., Bakker, A.B., Demerouti, E., \&Schaufeli, W.B. (2007). The role of personal resources in the job demands-resources model. International Journal of Stress Management, 14,121-141.

[83] Xanthopoulou, D., Bakker, A.B., Demerouti, E., \&Schaufeli, W.B. (2007b). Work engagement:A cycle of job and personal resources. Manuscript submitted for publication.

[84] Zhu, Y., Liu, C., Guo, B., Zhao, L., \& Lou, F. (2015). The impact of emotional intelligence on work engagement of 
International Journal of English Literature and Social Sciences, 5(4)

Jul-Aug 2020 /Available online: https://ijels.com/

registered nurses: The mediating role of organizational justice.

Journal of Clinical Nursing.24. 10.1111/jocn.12807. 